\title{
Comparison of site-specific gene expression levels in primary tumors and synchronous lymph node metastases in advanced gastric cancer
}

\author{
Akira Naruke • Mizutomo Azuma • Atsuko Takeuchi $\cdot$ Kenji Ishido • \\ Chikatoshi Katada - Tohru Sasaki • Katsuhiko Higuchi - Satoshi Tanabe • \\ Makoto Saegusa $\cdot$ Wasaburo Koizumi
}

Received: 7 November 2013/Accepted: 8 February 2014/Published online: 21 March 2014

(c) The International Gastric Cancer Association and The Japanese Gastric Cancer Association 2014

\begin{abstract}
Background Many malignant tumors consist of heterogeneous subpopulations of cells. This heterogeneity is associated with genetic characteristics. However, it remains unclear whether gene expression levels differ among specific sites of tumors in gastric cancer.

Methods We studied differences in gene expression levels among specific sites of primary tumors and synchronous lymph node metastases, using formalin-fixed, paraffinembedded specimens resected surgically from 48 patients with previously untreated advanced gastric cancer. Specimens were obtained by laser-captured microdissection from five regions: (1) nonneoplastic mucosa, (2) surface layer (mucosa) of the primary tumor (surface sections), (3) middle layer (submucosa) of the primary tumor (middle sections), (4) the deepest layer of the primary tumor (muscularis propria or deeper) at the site of deepest invasion (deep sections), and (5) level 1 synchronous lymph node metastasis (lymph node metastases). Expression levels of the following target genes were determined by quantitative real-time polymerase chain reaction: thymidylate synthase (TS), thymidine phosphorylase (TP), dihydropyrimidine dehydrogenase (DPD), epidermal growth factor receptor (EGFR), vascular endothelial
\end{abstract}

A. Naruke $(\square) \cdot$ M. Azuma - A. Takeuchi - K. Ishido ·

C. Katada - T. Sasaki - K. Higuchi - S. Tanabe - W. Koizumi

Department of Gastroenterology, Kitasato University School of

Medicine, 1-15-1 Kitasato, Minami-ku, Sagamihara,

Kanagawa 252-0374, Japan

e-mail: akira-n@kitasato-u.ac.jp

M. Saegusa

Department of Pathology, Kitasato University School of

Medicine, Sagamihara, Japan growth factor (VEGF), and hypoxia-inducible factor- $1 \alpha$ (HIF1 $\alpha$ ).

Results TP, DPD, EGFR, and HIF1 $\alpha$ gene expression levels were significantly higher in deep sections than in surface sections. TP, EGFR, VEGF, and HIF1 $\alpha$ gene expression levels were significantly higher in lymph node metastases than in surface sections. TP, DPD, EGFR, VEGF, and HIF1 $\alpha$ gene expression levels were positively correlated with the specific samples harvested from the tumors.

Conclusions Our results show that the expression levels of some genes in tumor cells can change in specific sites of tumors and can become higher in association with tumor progression.

Keywords Advanced gastric cancer - Site-specific gene expression level $\cdot$ Laser-captured microdissection

\section{Introduction}

Gastric cancer remains one of the most common malignancies worldwide, as well as one of the leading causes of cancer-related death [1].

Clinically, the histological types of intramucosal and submucosal sections of the same primary tumor often differ in patients with gastric cancer. The fact that some differentiated gastric cancers become undifferentiated cancers during the course of development has received considerable attention $[2,3]$.

It is widely accepted that many malignant tumors consist of heterogeneous subpopulations of cells. This heterogeneity is associated with a wide range of genetic, biochemical, and immunological characteristics. Previous studies have suggested that specific tumor cells within large heterogeneous tumor specimens are the forerunners of distant metastases [4]. 
Many biological differences thus exist between tumor cells in primary lesions and those in metastatic lesions. Furthermore, interactions of tumor cells with their environment may accentuate differences among tumor cells [5]. Despite the presence of different histological types of tumor cells within the same lesion, few studies have examined whether gene expression levels differ among specific sites in the same tumor or between primary tumors and metastatic lesions.

This study was designed to clarify differences in gene expression levels among specific sites in the same tumor or between primary tumors and synchronous lymph node metastases in advanced gastric cancer. Formalin-fixed, paraffin-embedded specimens surgically resected from patients with previously untreated stage II or III advanced gastric cancer were studied.

Laser-captured microdissection (LCM) was used to harvest cells from specific sites. LCM is an innovative technique that offers researchers a simple, reliable, rapid, and accurate tool for precise, contamination-free procurement of cells from tissue sections under direct visualization $[6,7]$. We quantified gene expression levels in tissue specimens obtained by LCM by real-time polymerase chain reaction (PCR), performed after preamplification.

In Japan, the standard treatment for stage II or III advanced gastric cancer [excluding pT1 and pT3 (penetrates serosa) pN0 disease] is S-1 (Taiho Pharmaceutical, Tokyo, Japan) as adjuvant chemotherapy after standard gastrectomy with D2 lymph node dissection [8]. S-1 is an oral formulation of 5-fluorouracil (5-FU, a fluoropyrimidine). It has been suggested that the expression levels of several genes related to fluoropyrimidine metabolism can be used to predict clinical outcomes in patients who receive 5-FU (fluoropyrimidine)-based chemotherapy [9]. Furthermore, recent studies have revealed that epidermal growth factor receptor (EGFR), vascular endothelial growth factor (VEGF), and hypoxia-inducible factor $1 \alpha$ (HIF1 $\alpha)$ participate in tumor progression, tumor-related angiogenesis, and metastasis. Gene expression levels of these factors might thus be useful predictors of clinical outcomes in gastric cancer [10-12]. We therefore selected thymidylate synthase (TS), thymidine phosphorylase (TP), dihydropyrimidine dehydrogenase (DPD), EGFR, VEGF, and HIF $1 \alpha$ as target genes in this study.

\section{Materials and methods}

Clinical methods

This retrospective study was approved by the Institutional Review Board of Kitasato University and was performed in accordance with the Declaration of Helsinki as amended in Somerest West.
The study group comprised 48 consecutive patients with stage II or III advanced gastric cancer. Written informed consent for the use of tissue specimens was obtained from all subjects in Kitasato University East Hospital. The patients underwent surgical resection of their primary tumors (gastrectomy) in the Department of Surgery, Kitasato University East Hospital from January 2001 through December 2004. All patients had a histopathological diagnosis of stage IIA or IIB (excluding T1 tumors), IIIA, IIIB, or IIIC gastric cancer; no evidence of residual tumor (R0), including specimens obtained by D2 lymph node dissection; and no evidence of hepatic metastasis or peritoneal dissemination, with negative results of cytological analysis of peritoneal washings. No patient had received preoperative chemotherapy.

The following clinicopathological characteristics were recorded according to the Japanese Classification of Gastric Carcinoma, issued by the Japanese Gastric Cancer Association [13]: age, sex, histological type, depth of tumor invasion $(\mathrm{T})$, extent of lymph node metastasis $(\mathrm{N})$, and disease stage.

\section{Laboratory methods}

\section{LCM of primary tumors and lymph node metastases}

Representative formalin-fixed, paraffin-embedded specimens of the primary tumor and synchronous lymph node metastasis surgically resected before adjuvant chemotherapy were selected by examining slides stained with hematoxylin and eosin. Tissue sections (thickness, $10 \mu \mathrm{m}$ ) were stained with nuclear fast red to enable visualization of histological features for LCM (Arcturus XT microdissection instrument; Arcturus, Sunnyvale, CA, USA) and to ensure that only tumor cells were studied.

Specimens were obtained by LCM from the following five sites: (1) the nonneoplastic mucosa (adjacent normal sections); (2) the surface layer of the primary tumor (surface sections), obtained from the mucosa; (3) the middle layer of the primary tumor (middle sections), obtained from the middle of the submucosa; (4) the deepest layer of the primary tumor (deep sections), obtained from sections at the site of deepest invasion of the muscularis propria, subserosa, or serosa; and (5) synchronous lymph node metastasis (lymph node metastases), obtained from the level 1 lymph node metastases. Specimens were carefully and selectively obtained from the designated sites, avoiding contamination with materials other than tumor cells.

\section{RNA extraction and cDNA synthesis}

Total RNA was isolated from tissue specimens obtained by LCM, using a NucleoSpin FFPE RNA/DNA kit (Takara 
Table 1 Primer sequences and probe sequences

\begin{tabular}{|c|c|c|}
\hline Gene & Primer and probe & Sequence \\
\hline \multirow[t]{3}{*}{$\beta$-actin } & Forward primer & 5'-GAGCGCGGCTACAGCTT-3' \\
\hline & Reverse primer & 5'-TCCTTAATGTCACGCACGATTT-3' \\
\hline & Probe & $5^{\prime}$-(FAM)ACCACCACGGCCGAGCGG(TAM)-3' \\
\hline \multirow[t]{3}{*}{ TS } & Forward primer & 5'-GCCTCGGTGTGCCTTTCA-3' \\
\hline & Reverse primer & 5'-CCCGTGATGTGCGCAAT-3' \\
\hline & Probe & $5^{\prime}$-(FAM)TCGCCAGCTACGCCCTGCTCA(TAM)- $3^{\prime}$ \\
\hline \multirow[t]{3}{*}{ TP } & Forward primer & 5'-CCTGCGGACGGAATCCT-3' \\
\hline & Reverse primer & 5'-GCTGTGATGAGTGGCAGGCT-3' \\
\hline & Probe & $5^{\prime}$-(FAM)CAGCCAGAGATGTGACAGCCACCGT(TAM)-3' \\
\hline \multirow[t]{3}{*}{ DPD } & Forward primer & 5'-AGGACGCAAGGAGGGTTTG-3' \\
\hline & Reverse primer & 5'-GTCCGCCGAGTCCTTACTGA-3' \\
\hline & Probe & $5^{\prime}$-(FAM)CAGTGCCTACAGTCTCGAGTCTGCCAGTG(TAM)-3 \\
\hline \multirow[t]{3}{*}{ EGFR } & Forward primer & 5'-TGCGTCTCTTGCCGGAAT-3' \\
\hline & Reverse primer & 5'-GGCTCACCCTCCAGAAGCTT-3' \\
\hline & Probe & $5^{\prime}$-(FAM)ACGCATTCCCTGCCTCGGCTG(TAM)-3' \\
\hline \multirow[t]{3}{*}{ VEGF } & Forward primer & 5'-AGTGGTCCCAGGCTGCAC-3' \\
\hline & Reverse primer & 5'-TCCATGAACTTCACCACTTCGT-3' \\
\hline & Probe & $5^{\prime}$-(FAM)ATGGCAGAAGGAGGAGGGCAGAATCA(TAM)-3' \\
\hline \multirow[t]{3}{*}{ HIF1 $\alpha$} & Forward primer & 5'-CGCTGGAGACACAATCATATC-3' \\
\hline & Reverse primer & $5^{\prime}$-TCCTCAAGTTGCTGGTCATC-3' \\
\hline & Probe & 5'-(FAM)TTTGGCAGCAACGACACAGAAACT(TAM)-3' \\
\hline
\end{tabular}

$T S$ thymidylate synthase, $T P$ thymidine phosphorylase, $D P D$ dihydropyrimidine dehydrogenase, $E G F R$ epidermal growth factor receptor, $V E G F$ vascular endothelial growth factor, HIFl $\alpha$ hypoxia-inducible factor- $1 \alpha$

Bio, Otsu, Japan) according to the manufacturer's instructions. Subsequently, a TURBO DNA-free kit (Life Technologies, Carlsbad, CA, USA) was used according to the instruction manual to completely remove all gDNA contamination. cDNA was synthesized with random primers and reverse transcriptase with the use of a High Capacity cDNA Reverse Transcription Kit (Life Technologies), following the manufacturer's instructions.

\section{Multiplex preamplification of cDNA targets}

To increase the sensitivity for quantification of relative gene expression levels, a multiplex PCR preamplification of the six target gene cDNAs and of $\beta$-actin cDNA was performed using a TaqMan PreAmp Master Mix Kit (Life Technologies), following the manufacturer's instructions. The pooled assay mix contained seven primers together in a final concentration of $0.2 \mu \mathrm{M}$. Subsequently, $12.5 \mu \mathrm{l}$ of the pooled assay mix $(0.2 \mu \mathrm{M})$ was combined with each cDNA sample and $25 \mu \mathrm{l}$ of TaqMan PreAmp Master Mix $(2 \times)$ in a final volume of $50 \mu \mathrm{l}$. Thermal cycling conditions were as follows: initial hold at $95{ }^{\circ} \mathrm{C}$ for $10 \mathrm{~min}$ and ten preamplification cycles of $15 \mathrm{~s}$ at $95^{\circ} \mathrm{C}$ and $4 \mathrm{~min}$ at $60{ }^{\circ} \mathrm{C}$. Primer sequences for the target gene cDNAs and $\beta$ actin cDNA are shown in Table 1.

\section{Real-time PCR}

Real-time PCR was carried out using LightCycler Software 2.0 (Roche Diagnostics, Indianapolis, IN, USA). Probe and primer sequences for the target gene cDNAs and $\beta$-actin cDNA are shown in Table 1. PCR was carried out in a final volume of $20 \mu \mathrm{l}$ with LightCycler TaqMan Master Mix (Roche Diagnostics), using $5.0 \mu \mathrm{l}$ preamplified cDNA, $10 \mu \mathrm{mol} / 1$ each primer, and $10 \mu \mathrm{mol} / 1$ probe for each target gene cDNA. Cycling conditions were $95^{\circ} \mathrm{C}$ for $10 \mathrm{~min}$ followed by 45 cycles at $95{ }^{\circ} \mathrm{C}$ for $10 \mathrm{~s}, 60{ }^{\circ} \mathrm{C}$ for $20 \mathrm{~s}$, and $72{ }^{\circ} \mathrm{C}$ for $1 \mathrm{~s}$.

\section{Quantification of target gene mRNA levels}

Relative gene expression levels were determined by the standard curve method. Standard curves for target gene cDNAs and $\beta$-actin cDNA were generated using a fivefold serially diluted solution of preamplified cDNA from Stratagene QPCR Human Reference Total RNA (\#750500; Stratagene, Orange County, CA, USA).

The target gene expression level was calculated from the standard curve, and quantitative normalization of cDNA in each sample was performed using the expression of the $\beta$ actin gene as an internal control. Finally, target gene cDNA 
Table 2 Characteristics of the patients

\begin{tabular}{|c|c|}
\hline Characteristics & $n=48$ \\
\hline \multicolumn{2}{|l|}{ Age (years) } \\
\hline Mean \pm SD (range) & $60.9 \pm 8.9(41-78)$ \\
\hline \multicolumn{2}{|l|}{ Sex } \\
\hline Male & 33 \\
\hline Female & 15 \\
\hline \multicolumn{2}{|c|}{ Histological type of surface section of primary tumor } \\
\hline pap & 0 \\
\hline tub1 & 7 \\
\hline tub2 & 9 \\
\hline por1 & 18 \\
\hline por2 & 7 \\
\hline sig & 4 \\
\hline muc & 3 \\
\hline \multicolumn{2}{|l|}{ Macroscopic type } \\
\hline Type 1 & 2 \\
\hline Type 2 & 9 \\
\hline Type 3 & 19 \\
\hline Type 4 & 4 \\
\hline Type 5 & 14 \\
\hline \multicolumn{2}{|l|}{$\mathrm{T}$} \\
\hline 2 & 3 \\
\hline 3 & 16 \\
\hline $4 a$ & 28 \\
\hline $4 b$ & 1 \\
\hline \multicolumn{2}{|l|}{$\mathrm{N}$} \\
\hline 0 & 8 \\
\hline 1 & 14 \\
\hline 2 & 12 \\
\hline $3 a$ & 9 \\
\hline $3 b$ & 5 \\
\hline \multicolumn{2}{|l|}{ Stage } \\
\hline IIA & 4 \\
\hline IIB & 13 \\
\hline IIIA & 12 \\
\hline IIIB & 6 \\
\hline IIIC & 13 \\
\hline
\end{tabular}

pap papillary adenocarcinoma, tubl well-differentiated tubular adenocarcinoma, $t u b 2$ moderately differentiated tubular adenocarcinoma, por1 poorly differentiated adenocarcinoma solid type, por 2 poorly differentiated adenocarcinoma nonsolid type, sig signet-ring cell carcinoma; muc, mucinous adenocarcinoma, $T$ depth of tumor invasion, $N$ extent of lymph node metastasis

levels were expressed as ratios relative to the $\beta$-actin cDNA level.

\section{Statistical analysis}

All statistical analyses were carried out using SPSS, version 17.0 (SPSS Japan, Tokyo, Japan). The Mann-Whitney
Table 3 Histological heterogeneity

\begin{tabular}{|c|c|c|c|c|}
\hline $\begin{array}{l}\text { Histolog } \\
\text { tub2 a }\end{array}$ & $\begin{array}{l}\text { type of s } \\
\text { ocarcinom }\end{array}$ & ce section & b1 or & $n=16$ \\
\hline $\begin{array}{l}\text { Histolos } \\
\text { tumor }\end{array}$ & heteroge & $y$ of prim & & $5(31.3)$ \\
\hline $\begin{array}{l}\text { Histolos } \\
\text { sectiol }\end{array}$ & $\begin{array}{l}\text { heteroge } \\
\text { d lymph } 1\end{array}$ & $\begin{array}{l}y \text { between } \\
\text { metastas }\end{array}$ & $\begin{array}{l}\text { face } \\
\%)\end{array}$ & $7(43.8)$ \\
\hline Patient & $\begin{array}{l}\text { Surface } \\
\text { section }\end{array}$ & $\begin{array}{l}\text { Middle } \\
\text { section }\end{array}$ & $\begin{array}{l}\text { Deep } \\
\text { section }\end{array}$ & $\begin{array}{l}\text { Lymph } \\
\text { node metastasis }\end{array}$ \\
\hline No. 1 & tub2 & tub2 & por1 & \\
\hline No. 2 & tub2 & por2 & por2 & \\
\hline No. 3 & tub1 & tub1 & por1 & por1 \\
\hline No. 4 & tub2 & tub2 & por1 & por1 \\
\hline No. 5 & tub2 & tub2 & por1 & por1 \\
\hline No. 6 & tub1 & tub1 & tub1 & por1 \\
\hline No. 7 & tub1 & tub1 & tub2 & por1 \\
\hline No. 8 & tub2 & tub2 & tub2 & por1 \\
\hline No. 9 & tub2 & tub2 & tub2 & por1 \\
\hline
\end{tabular}

tub1 well-differentiated tubular adenocarcinoma, tub2 moderately differentiated tubular adenocarcinoma, porl poorly differentiated adenocarcinoma solid type, por 2 poorly differentiated adenocarcinoma nonsolid type

test was used to evaluate the expression level of each target gene in each section studied. Spearman's rank correlation coefficient was used to evaluate correlations between target gene and site. $p$ values $<0.05$ were considered to indicate statistical significance.

\section{Results}

\section{Clinicopathological characteristics}

The study group consisted of 48 patients ( 33 men and 15 women) with a mean age of 60.9 years. The histological type of the surface sections of the primary tumors was papillary adenocarcinoma (pap) in no patient, well-differentiated tubular adenocarcinoma (tub1) in 7, moderately differentiated tubular adenocarcinoma (tub2) in 9, poorly differentiated adenocarcinoma solid type (por1) in 18, poorly differentiated adenocarcinoma nonsolid type (por2) in 7 , signet-ring cell carcinoma (sig) in 4 , and mucinous adenocarcinoma (muc) in 3 . The macroscopic type of the primary tumors was type 1 in 2 , type 2 in 9 , type 3 in 19 , type 4 in 4 , and type 5 in 14 . The depth of wall invasion by the primary tumor $(\mathrm{T})$ was $\mathrm{T} 2$ in 3 patients, $\mathrm{T} 3$ in 16, T4a in 28 , and $\mathrm{T} 4 \mathrm{~b}$ in 1 . Lymph node metastasis $(\mathrm{N})$ was $\mathrm{N} 0$ in 8 patients, $\mathrm{N} 1$ in $14, \mathrm{~N} 2$ in $12, \mathrm{~N} 3 \mathrm{a}$ in 9 , and N3b in 5 . Disease stage was stage IIA in 4 patients, stage IIB in 13, stage IIIA in 12 , stage IIIB in 6 , and stage IIIC in 13 . Patient characteristics are summarized in Table 2. 

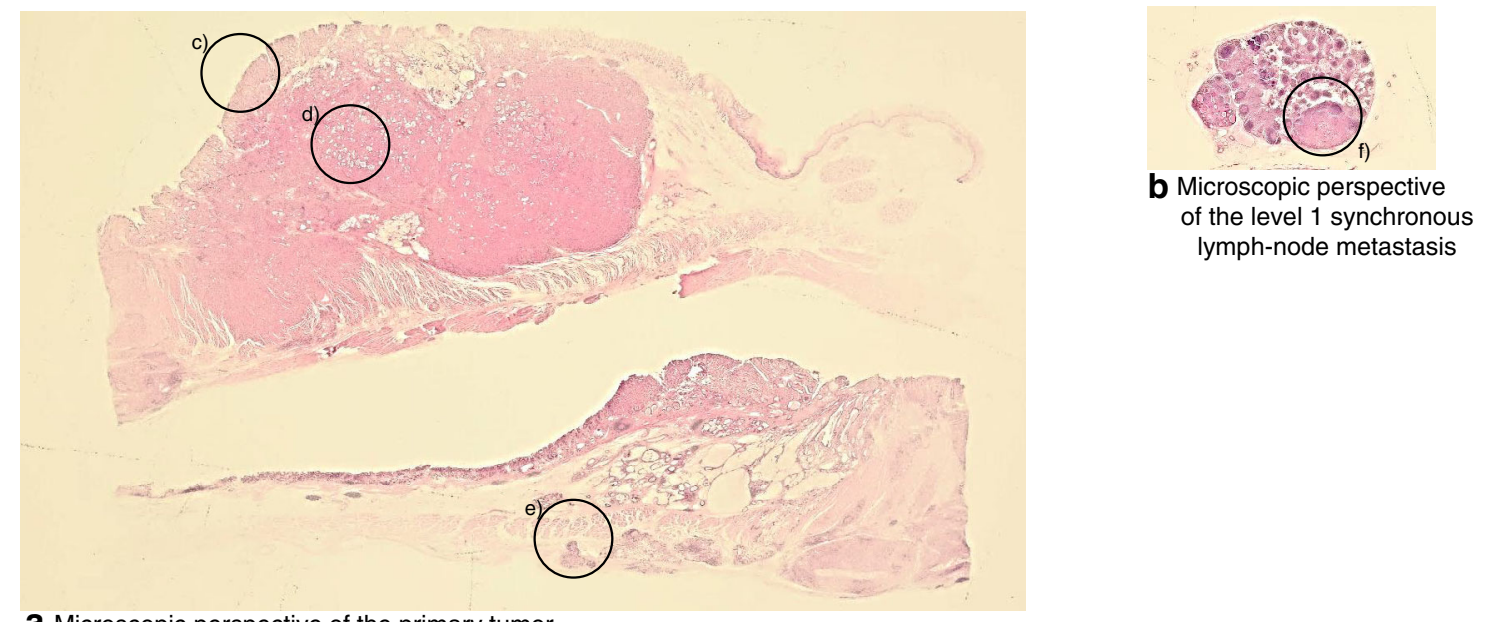

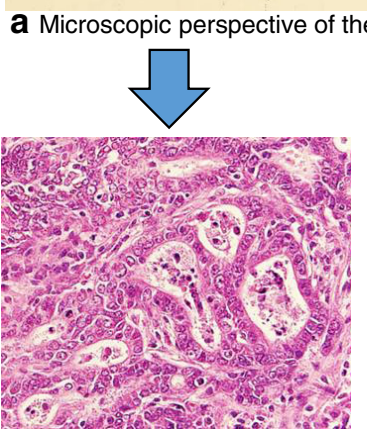

C Surface section

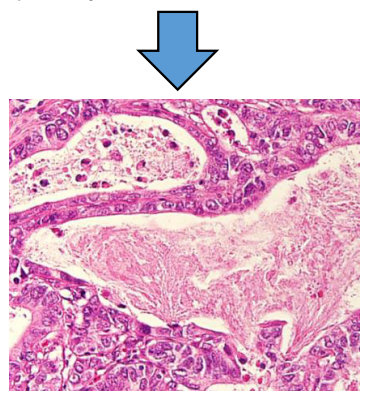

d Middle section

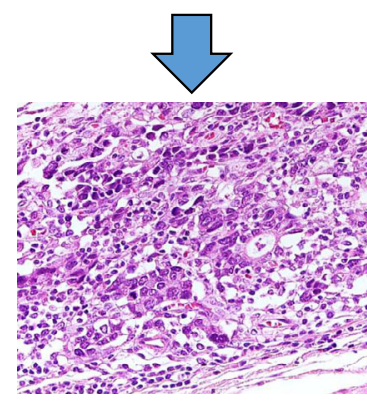

e Deep section

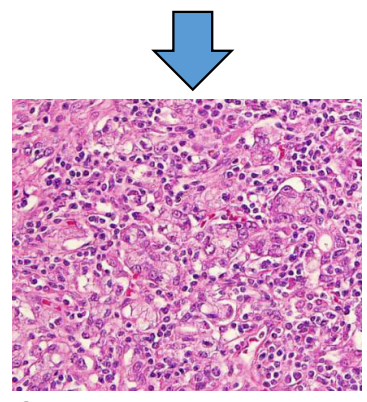

f Lymph-node metastasis
Fig. 1 A typical case showing the histological heterogeneity among different sites of tumor [hematoxylin and eosin (H\&E) staining]. a Microscopic perspective of the primary tumor. b Microscopic perspective of the level 1 synchronous lymph node metastases. c Histological type of the surface section of the primary tumor was well-differentiated tubular adenocarcinoma (tub1). d Histological

In the five patients with histological heterogeneity in their primary tumors, the histological type of the surface sections of their primary tumors was tub1 or tub2 adenocarcinoma, which changed to por1 or por 2 adenocarcinoma as the depth of the tumor invasion increased (Table 3). In the seven patients showing histological heterogeneity between the surface sections of their primary tumors and lymph node metastases, the histological type of the surface sections of the primary tumors was also tub1 or tub2 adenocarcinoma (Table 3). A typical case showing histological heterogeneity among specific tumor sites is shown in Fig. 1a-f.

\section{Target gene expression levels}

Expression levels (relative cDNA levels) of the target genes are presented as ratios of the gene of interest to the internal reference gene ( $\beta$-actin), which provided a normalization factor for the amount of cDNA. Table 4 shows the expression levels of each target gene. Nearly all target gene expression levels were higher in tumor tissue than in type of the middle section of the primary tumor was well-differentiated tubular adenocarcinoma (tub1). e Histological type of the deep section of the primary tumor was poorly differentiated adenocarcinoma, solid type (por1). f Histological type of the level 1 synchronous lymph node metastasis was poorly differentiated adenocarcinoma, solid type (por1). a, $\mathbf{b} \times 1 ; \mathbf{c}-\mathbf{f} \times 200$

nonneoplastic mucosa. The expression levels of the TS, EGFR, and HIF1 $\alpha$ genes did not differ significantly between the surface sections and the nonneoplastic mucosa (Table 4).

In each of the dissected sites, there were no significant differences in target gene expression levels among the histological types (pap, tub1, tub2 or por1, por2, muc). There was no correlation between the gene expression levels and clinical outcomes.

Target gene expression levels in specific sites of primary tumors and synchronous lymph node metastases are shown in Fig. 2a-f.

TS gene expression levels did not differ significantly among the dissected sites of the tumors (Fig. 2a).

TP, DPD, EGFR, and HIF1 $\alpha$ gene expression levels in deep sections were significantly higher than those in surface sections $(p=0.002, p=0.035, p=0.016$, $p<0.001$, respectively) (Fig. $2 \mathrm{~b}-\mathrm{d}, \mathrm{f}$ ). The HIF $1 \alpha$ gene expression level was significantly higher in deep sections than in middle sections and was significantly higher in middle sections than in surface sections $(p=0.017$, $p=0.021$, respectively) (Fig. 2f). 
Table 4 Target gene expression [mean \pm SD, (range)]

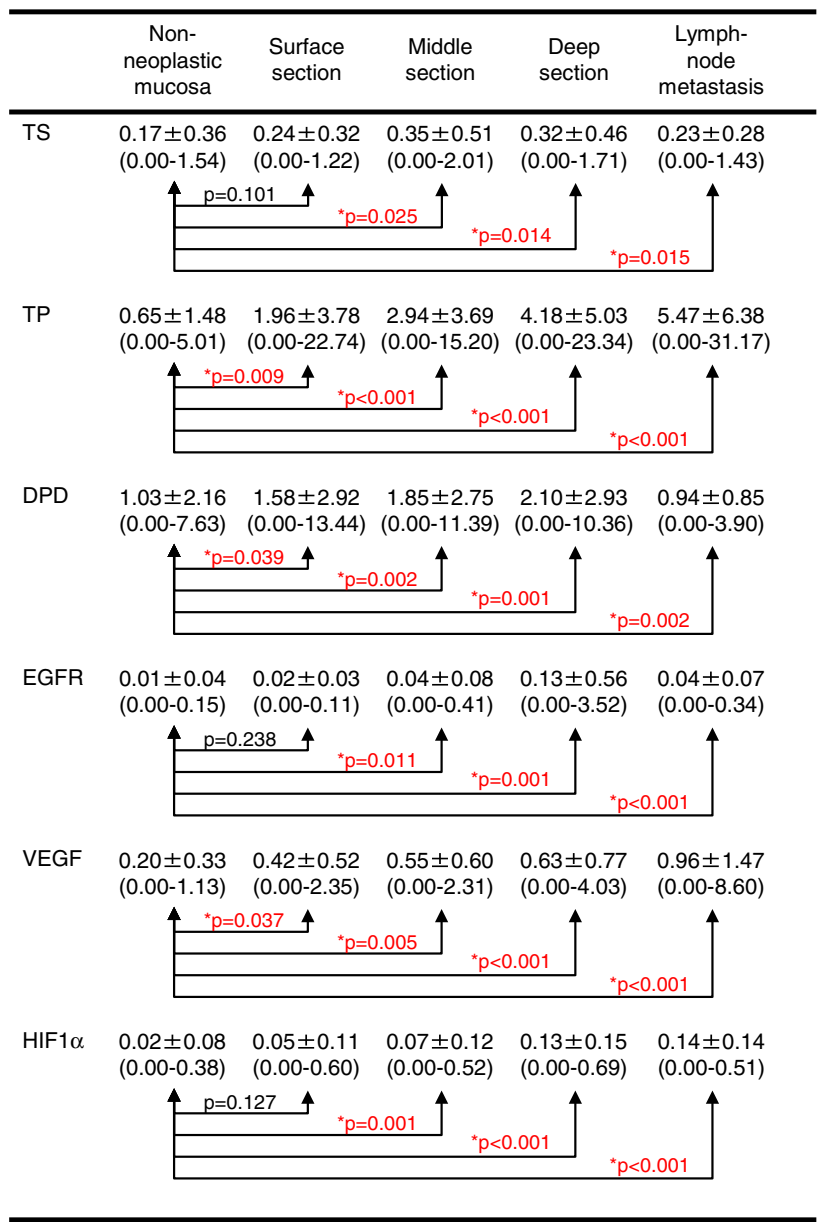

$T S$ thymidylate synthase, $T P$ thymidine phosphorylase, $D P D$ dihydropyrimidine dehydrogenase, EGFR epidermal growth factor receptor, VEGF vascular endothelial growth factor, $H I F 1 \alpha$ hypoxiainducible factor- $1 \alpha$

TP, EGFR, VEGF, and HIF1 $\alpha$ gene expression levels were significantly higher in lymph node metastases than in surface sections of primary tumors $(p=0.002, p=0.002$, $p=0.005, p<0.001)$ (Fig. $2 \mathrm{~b}, \mathrm{~d}-\mathrm{f}$ ). The HIF1 $\alpha$ gene expression level was significantly higher in lymph node metastases than in the middle sections of primary tumors $(p=0.025)$ (Fig. 2f).

TP, DPD, EGFR, VEGF, and HIF1 $\alpha$ gene expression levels positively correlated with the dissected sections of the tumors in a site-specific manner (TP: $r=0.399$, $p<0.001$; DPD: $r=0.250, p=0.001$; EGFR: $r=0.346$, $p<0.001 ; \quad$ VEGF: $r=0.323, \quad p<0.001 ; \quad$ HIF $1 \alpha$ : $r=0.449, p<0.001$ ) (Fig. 2b-f).

\section{Discussion}

Our study showed that expression levels of the TP, DPD, EGFR, and HIF1 $\alpha$ genes were greater in deep sections than in surface sections of primary tumors. In addition, expression levels of the TP, EGFR, VEGF, and HIF1 $\alpha$ genes were higher in lymph node metastases than in surface sections of primary tumors. All target genes except TS showed site-specific positive correlations between gene expression level and the dissection sites of the tumors (including lymph node metastases) in our study. Several studies have also reported high expression levels of genes related to growth factors, cell cycles, and cell motility in lymph node metastases [14], which is in part consistent with our results.

In gastric cancer, tumor progression and lymph node metastases are sometimes associated with the dedifferentiation of differentiated adenocarcinoma to undifferentiated adenocarcinoma [2, 3, 15]. Among the 16 patients in whom the histological type of the surface layer was tub1 or tub2 adenocarcinoma in our study, 5 patients $(31.3 \%)$ showed histological heterogeneity within their primary tumors and $7(43.8 \%)$ showed histological heterogeneity between their primary tumors and lymph node metastases. Submucosal transformation to poorly differentiated adenocarcinoma is thought to increase malignant potential and to promote lymphatic vessel invasion and lymph node metastasis [16].

Few studies have compared the histological type of primary tumors with that of synchronous lymph node metastases. Genetic changes most likely precede histopathological changes.

The finding that the TP, VEGF, and HIF1 $\alpha$ genes were simultaneously expressed at high levels is consistent with angiogenesis pathways proposed by recent studies [17]. However, many aspects of the relationships among different genes remain uncertain. Further elucidation must await the results of future studies. Whether there is a direct causal relationship between TP and VEGF gene expression remains unclear, but TP is known to participate in angiogenesis [18]. TP expression in tumor cells is closely linked to microvascular density, and microvascular density in tumors strongly correlates with VEGF expression [19]. In addition, TP has been shown to convey resistance to hypoxia-induced apoptosis [20] and may also participate in tumor invasion and metastasis in gastric cancer [21-23]. However, vascular endothelial growth factor receptor (VEGFR) was not examined in this study. Therefore, we could not clarify the relationship between angiogenesis and expression of the target genes. 

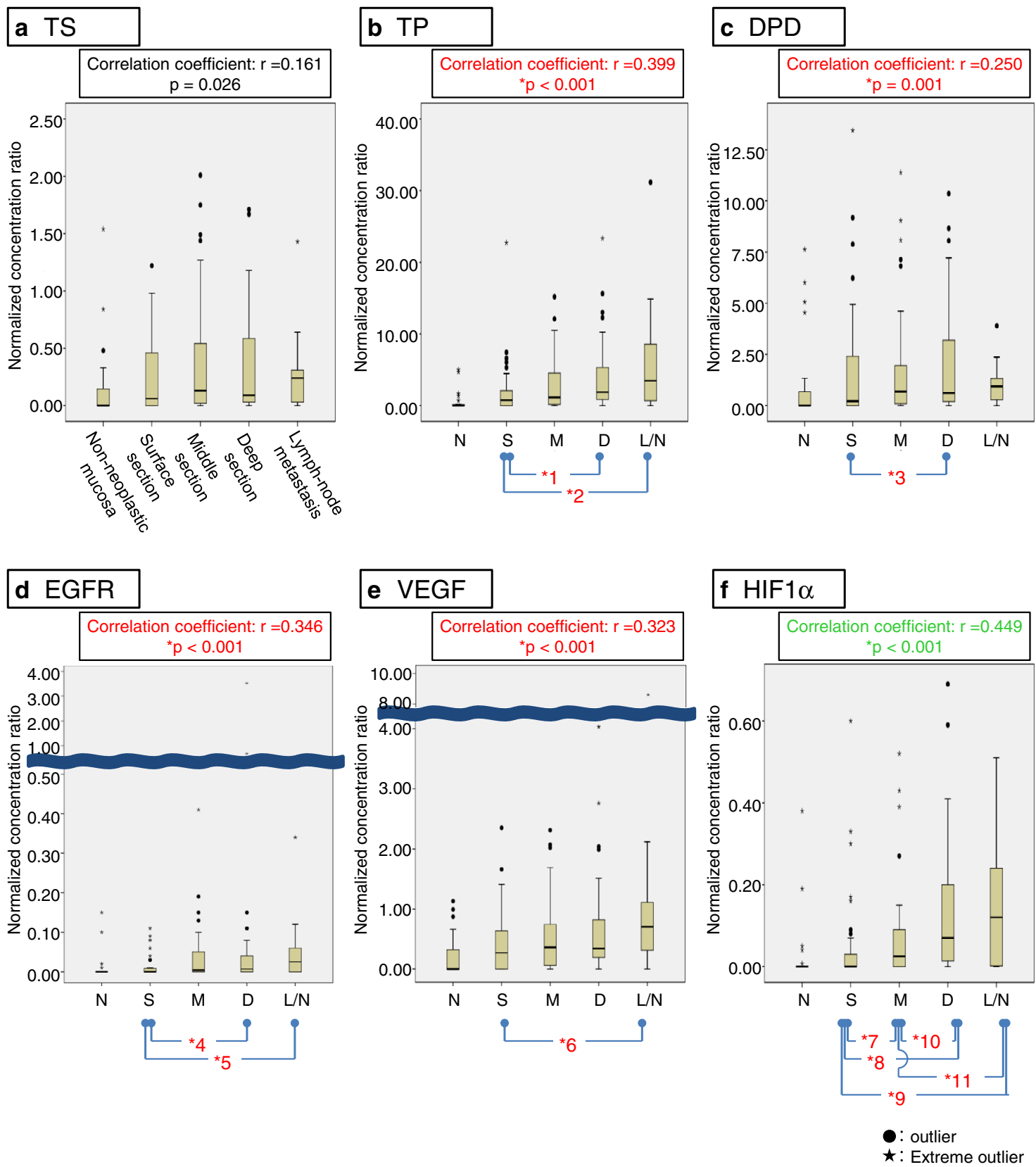

$\mathrm{N}$, non-neoplastic mucosa; $\mathrm{S}$, surface section; $\mathrm{M}$, middle section; $\mathrm{D}$, deep section; L/N, lymph-node metastasis

${ }^{*} 1: p=0.002,{ }^{\star} 2: p=0.002,{ }^{*} 3: p=0.035,{ }^{*} 4: p=0.016,{ }^{*} 5: p=0.002,{ }^{*} 6: p=0.005$,

${ }^{*} 7: p=0.021,{ }^{*} 8: p<0.001,{ }^{*} 9: p<0.001,{ }^{*} 10: p=0.017,{ }^{*} 11: p=0.025$

Fig. 2 Box and whisker plots of the target genes and correlations among expression levels: target gene expression levels in specific sites of primary tumors and synchronous lymph node metastases. Five of the six genes (excluding TS) showed site-specific positive correlations between the expression level and dissected site of the

The HIF1 $\alpha$ gene is expressed at high levels under hypoxic conditions and finally binds to hypoxia-responsive elements (HREs), its target gene, thereby inducing transcription of various growth factors, such as VEGF and tumors (including lymph node metastases): thymidylate synthase (TS) (a); thymidine phosphorylase $(T P)(\mathbf{b})$; dihydropyrimidine dehydrogenase $(D P D)(\mathbf{c})$; epidermal growth factor receptor $(E G F R)(\mathbf{d})$; vascular endothelial growth factor $(V E G F)(\mathbf{e})$; hypoxia-inducible factor-1 $\alpha(H I F 1 \alpha)(\mathbf{f})$

glucose transporter 1 (GLUT1), which is involved in active transport of glucose [24-26]. In gastric cancer, HIF1 $\alpha$ also participates in angiogenesis, tumor invasion, and metastasis [27]. However, HIF1a gene expression may be 
controlled at the transcription level by some other factor(s) besides hypoxia [28].

As tumors grow in diameter, the tissue becomes hypoxic [29]. We did not measure tissue oxygen tension in our study and therefore could not clarify the relationship between hypoxia and expression levels of the target genes.

TP expression is high at the invasive edge of tumors [30]. Histopathologically, TP expression is higher in undifferentiated cancer than in differentiated cancer [31]. HIF1 $\alpha$ expression is also increased in undifferentiated cancer [32]. In fact, the expression levels of some genes in our study were positively correlated with tumor progression, although there were no significant differences among the histological types (pap, tub1, tub2 or por1, por2, muc) in any dissected sites studied.

Our results together with these findings suggest that tumor cell genes change as a response to environmental factors such as hypoxia, either before or simultaneously with dedifferentiation-induced histological changes or the acquisition of metastatic activity. It is still unclear whether environmental factors or malignant potential initially influences changes in the expression of some genes; however, we suppose that malignant potential increases as a result of changes in gene expression in a similar manner as genetic changes precede histological changes.

Because we consider malignant potential a cell-specific factor, even if tumor cells originally have it, stimulation by environmental factors is the trigger of gene expression changes. We are planning to investigate the effects of $\mathrm{Ki}$ 67 gene and protein expression on cell proliferation potential in a similar site-specific situation. The results of these studies may shed light on which factors predominantly affect gene expression.

The existence of a pathway that can explain these laboratory findings is not yet proven, and further studies are needed to clarify the relationship between angiogenesis and changes in gene expression levels. In summary, our study demonstrated that the expression levels of some genes in tumor cells can change in specific sites of tumors and can become higher in association with tumor progression.

\begin{abstract}
Acknowledgments This research received no specific grant from any funding agency in the public, commercial, or not-for-profit sectors.

Clarification of site-specific differences in gene expression levels in gastric cancer is likely to contribute to our understanding of the properties of tumors and to provide useful information for the design of therapeutic strategies for gastric cancer.
\end{abstract}

Conflict of interest The authors disclose no potential conflicts of interest.

\section{References}

1. Parkin DM, Bray F, Ferlay J, Pisani P. Global cancer statistics, 2002. CA Cancer J Clin. 2005;55(2):74-108.
2. Endoh Y, Tamura G, Watanabe H, Ajioka Y, Motoyama T. The common 18-base pair deletion at codons 418-423 of the E-cadherin gene in differentiated-type adenocarcinomas and intramucosal precancerous lesions of the stomach with the features of gastric foveolar epithelium. J Pathol. 1999;189(2):201-6.

3. Saito A, Shimoda T, Nakanishi Y, Ochiai A, Toda G. Histologic heterogeneity and mucin phenotypic expression in early gastric cancer. Pathol Int. 2001;51(3):165-71.

4. Portera CA Jr, Berman RS, Ellis LM. Molecular determinants of colon cancer metastasis. Surg Oncol. 1998;7(3-4):183-95.

5. Fidler IJ. Critical determinants of metastasis. Semin Cancer Biol. 2002;12(2):89-96.

6. Emmert-Buck MR, Bonner RF, Smith PD, Chuaqui RF, Zhuang $\mathrm{Z}$, Goldstein SR, et al. Laser capture microdissection. Science. 1996;274(5289):998-1001.

7. Bohm M, Wieland I, Schutze K, Rubben H. Microbeam MOMeNT: non-contact laser microdissection of membranemounted native tissue. Am J Pathol. 1997;151(1):63-7.

8. Japanese gastric cancer treatment guidelines 2010 (ver. 3). Gastric Cancer 2011;14(2):113-123.

9. Ichikawa W. Prediction of clinical outcome of fluoropyrimidinebased chemotherapy for gastric cancer patients, in terms of the 5-fluorouracil metabolic pathway. Gastric Cancer. 2006;9(3): 145-55.

10. Lieto E, Ferraraccio F, Orditura M, Castellano P, Mura AL, Pinto $M$, et al. Expression of vascular endothelial growth factor (VEGF) and epidermal growth factor receptor (EGFR) is an independent prognostic indicator of worse outcome in gastric cancer patients. Ann Surg Oncol. 2008;15(1):69-79.

11. Wang X, Cao W, Mo M, Wang W, Wu H, Wang J. VEGF and cortactin expression are independent predictors of tumor recurrence following curative resection of gastric cancer. J Surg Oncol. 2010;102(4):325-30.

12. Nakamura J, Kitajima Y, Kai K, Mitsuno M, Ide T, Hashiguchi $\mathrm{K}$, et al. Hypoxia-inducible factor-1alpha expression predicts the response to 5-fluorouracil-based adjuvant chemotherapy in advanced gastric cancer. Oncol Rep. 2009;22(4):693-9.

13. Japanese Gastric Cancer Association. Japanese classification of gastric carcinoma, 3rd English edition. Gastric Cancer. 2011;14(2): $101-12$.

14. Xie HL, Li ZY, Gan RL, Li XJ, Zhang QL, Hui M, et al. Differential gene and protein expression in primary gastric carcinomas and their lymph node metastases as revealed by combined cDNA microarray and tissue microarray analysis. J Dig Dis. 2010;11(3):167-75.

15. Nakamura T, Yao T, Kabashima A, Nishiyama K, Maehara Y, Tsuneyoshi M. Loss of phenotypic expression is related to tumour progression in early gastric differentiated adenocarcinoma. Histopathology (Oxf). 2005;47(4):357-67.

16. Mita T, Shimoda T. Risk factors for lymph node metastasis of submucosal invasive differentiated type gastric carcinoma: clinical significance of histological heterogeneity. J Gastroenterol. 2001;36(10):661-8.

17. Fox SB, Gasparini G, Harris AL. Angiogenesis: pathological, prognostic, and growth-factor pathways and their link to trial design and anticancer drugs. Lancet Oncol. 2001;2(5):278-89.

18. Miyadera K, Sumizawa T, Haraguchi M, Yoshida H, Konstanty W, Yamada Y, et al. Role of thymidine phosphorylase activity in the angiogenic effect of platelet derived endothelial cell growth factor/thymidine phosphorylase. Cancer Res. 1995;55(8): 1687-90.

19. Han HS, Hwang TS. Angiogenesis in gastric cancer: importance of the thymidine phosphorylase expression of cancer cells as an angiogenic factor. Oncol Rep. 2007;17(1):61-5.

20. Kitazono M, Takebayashi Y, Ishitsuka K, Takao S, Tani A, Furukawa T, et al. Prevention of hypoxia-induced apoptosis by 
the angiogenic factor thymidine phosphorylase. Biochem Biophys Res Commun. 1998;253(3):797-803.

21. Yu EJ, Lee Y, Rha SY, Kim TS, Chung HC, Oh BK, et al. Angiogenic factor thymidine phosphorylase increases cancer cell invasion activity in patients with gastric adenocarcinoma. Mol Cancer Res. 2008;6(10):1554-66.

22. Maeda K, Kang SM, Ogawa M, Onoda N, Sawada T, Nakata B, et al. Combined analysis of vascular endothelial growth factor and platelet-derived endothelial cell growth factor expression in gastric carcinoma. Int J Cancer. 1997;74(5):545-50.

23. Takebayashi Y, Miyadera K, Akiyama S, Hokita S, Yamada K, Akiba S, et al. Expression of thymidine phosphorylase in human gastric carcinoma. Jpn J Cancer Res. 1996;87(3):288-95.

24. Semenza GL. Regulation of physiological responses to continuous and intermittent hypoxia by hypoxia-inducible factor 1 . Exp Physiol. 2006;91(5):803-6.

25. Semenza GL. Regulation of tissue perfusion in mammals by hypoxia-inducible factor 1. Exp Physiol. 2007;92(6):988-91.

26. Ikeda E. Cellular response to tissue hypoxia and its involvement in disease progression. Pathol Int. 2005;55(10):603-10.

27. Isobe T, Aoyagi K, Koufuji K, Shirouzu K, Kawahara A, Taira T, et al. Clinicopathological significance of hypoxia-inducible factor-1 alpha (HIF-1alpha) expression in gastric cancer. Int J Clin Oncol. 2013;18(2):293-304.
28. Yoshida $\mathrm{T}$, Hashimura $\mathrm{M}$, Mastumoto $\mathrm{T}$, Tazo $\mathrm{Y}$, Inoue $\mathrm{H}$, Kuwata $\mathrm{T}$, et al. Transcriptional upregulation of HIF-1alpha by NF-kappaB/p65 and its associations with beta-catenin/p300 complexes in endometrial carcinoma cells. Lab Invest. 2013;93: 1184-93.

29. Thomlinson RH, Gray LH. The histological structure of some human lung cancers and the possible implications for radiotherapy. Br J Cancer. 1955;9(4):539-49.

30. Shimaoka S, Matsushita S, Nitanda T, Matsuda A, Nioh T, Suenaga $\mathrm{T}$, et al. The role of thymidine phosphorylase expression in the invasiveness of gastric carcinoma. Cancer (Phila). 2000;88(10):2220-7.

31. Kimura H, Konishi K, Kaji M, Maeda K, Yabushita K, Miwa A. Correlation between expression levels of thymidine phosphorylase (dThdPase) and clinical features in human gastric carcinoma. Hepatogastroenterology. 2002;49(45):882-6.

32. Qiu MZ, Han B, Luo HY, Zhou ZW, Wang ZQ, Wang FH, et al. Expressions of hypoxia-inducible factor-1alpha and hexokinaseII in gastric adenocarcinoma: the impact on prognosis and correlation to clinicopathologic features. Tumour Biol. 2011;32(1): $159-66$. 